\title{
INFORMAÇÃO E PLANEJAMENTO CORPORATIVO: A CONSULTORA DELOITTE E SUAS ARTICULAÇÕES NO TERRITÓRIO BRASILEIRO
}

\author{
INFORMATION AND CORPORATE PLANNING: DELOITTE CONSULTANT \\ AND ITS TRANSACTIONS IN BRAZILIAN TERRITORY
}

\author{
INFORMATION ET PLANIFICATION COOPERATIVE: DELOITTE \\ CONSEIL ET SES ARTICULATION SUR LE TERRITOIRE BRÉSILIEN
}

\author{
Sérgio Henrique de Oliveira Teixeira - Instituto Federal de Educação, Ciência e Tecnologia do Sul de Minas Gerais \\ Minas Gerais - Poços de Caldas - Brasil \\ sergio.teixeira@ifsuldeminas.edu.br
}
Adriana Maria Bernardes Silva - Universidade Estadual de Campinas - São Paulo - Campinas - Brasil abernardes@ige.unicamp.br

\section{Resumo}

Este artigo tem como objetivo analisar a ascendência de novos agentes corporativos no planejamento territorial brasileiro. Identificamos, sobretudo, as reestruturações produtivas no sistema capitalista que fizeram emergir empresas que controlam a informação organizacional ligadas à gerência dos bancos de dados das grandes corporações internacionais e das infraestruturas territoriais das formações socioespaciais. Em especial, analisamos o papel da consultora global Deloitte no uso e na produção do espaço brasileiro, assim como a sua atuação no planejamento. Para tanto, será feita uma análise apurada da empresa, identificando sua tipologia de serviços, sua topologia na formação socioespacial brasileira e a relação de seus escritórios com a rede de cidades.

Palavras-chave: Informação Organizacional. Planejamento Corporativo. Empresas de Consultoria. Deloitte. Rede de Cidades.

\section{Abstract}

This article aims to analyze the ascendancy of new corporate agents in Brazilian territorial planning. We have identified, above all, productive restructuring in capitalist system that has led to the emergence of companies that control organizational information linked to the management of large international corporations databases and the territorial infrastructures of socio-spatial formations. In particular, we analyze the role of Deloitte global consultant in the use and production of Brazilian space, as well as its role in planning. In order to that, a detailed analysis of the company will be made, identifying its service typology, its topology in Brazilian sociospatial formation and the relationship of its offices with the city network.

Keywords: Organizational Information. Corporate Planning. Consultancy Companies. Deloitte. City Network.

\section{Résumè}

Cet article vise analyser l'ascendant de nouveaux d'entreprise responsable dans la planification territoriale brésilienne. Nous avons identifié des restructurations productives du système capitaliste qui ont fait ressorti les entreprises dont cela controle des informations organisationnelles liées aux bases de données gères par des banques concernat à des grandes entreprises internationales et des infrastructures territoriales de formations socio-spatiales. Nous avons remarqué du rôle et de l'action du consultant mondial Deloitte dans l'utilisation et 
la production de l'espace brésilien, ainsi que son intervention qui cela applique à la planification. À cet effet, on fera une analyse détaillée de la entreprise, en train de identifier une typologie de services, sa topologie sur ce qui forme la socio-spatiale brésilienne et le lien commercial de ses bureaux avec le réseau de villes.

Mots- clés: Information sur l'organisation. Planification Cooperative. Cabinets de conseil. Deloitte. Réseau de villes.

\section{Introdução}

A informação não apenas está presente nas coisas, nos objetos técnicos, que formam o espaço, como ela é necessária à ação realizada sobre essas coisas. A informação é o vetor fundamental do processo social e os territórios são, desse modo, equipados para facilitar a sua circulação. (Santos, 1996, p. 191).

No último quartel do século XX, a mundialização do capital, articulada com os avanços das técnicas da informação e da produção, aprofundou a divisão territorial do trabalho, tendo como base a reestruturação produtiva e a revolução informacional (Braverman, 1987; Lojkine, 1995; Antunes, 1999). Ambas as mudanças, iniciadas a partir da década de 1970, possibilitaram a aceleração do tempo de rotação do capital, ao mesmo tempo que tornou o processo produtivo cada vez mais dependente das articulações das informações estratégicas. A informação e o território passaram à linha de frente do controle da produção em diversos espaços nacionais. Nesse contexto, o uso e articulação das informações estratégicas tornaram-se fundamentais para o exercício do planejamento territorial.

Nossa interpretação desse processo segue aqueles estudos que propõem ir além do que se entende frequentemente por poder da informação como estruturador do espaço e do sistema produtivo. Falamos, principalmente, do esforço em identificar a informação como elemento cada vez mais importante para organizar os circuitos espaciais produtivos globais e seus círculos de cooperação ${ }^{1}$ sem, com isso, cair em um fetichismo informacional ${ }^{2}$. Portanto, buscamos identificar os elementos que possibilitaram a ascendência de novos agentes corporativos na organização do capitalismo, identificando, sobretudo, as mudanças organizacionais que fizeram emergir o papel da informação e da gerência, associado aos bancos de dados das empresas de consultoria no planejamento do território.

Entre esses agentes, identificamos aqueles ligados ao setor das consultorias. Trata-se de corporações globais que se utilizam das informações organizacionais para operar o planejamento corporativo 
do território. Em especial, analisamos a consultora global Deloitte, identificando a tipologia de seus serviços e a topologia de seus escritórios, articuladas à rede de cidades brasileiras.

\section{Informação, reestruturação produtiva e uso do território}

O uso do território (Santos, 1996; Santos; Silveira, 2001) se realiza, do ponto de vista da ação hegemônica, por meio do controle que o Estado e as corporações fazem dos objetos técnicos que operam em sistema sobre as materialidades territoriais. O desenvolvimento das ciências, das técnicas e dos sistemas de informações impregnaram os sistemas de objetos, mudando as funcionalidades e dando origem a um novo meio geográfico que se desenvolveu por meio de quantidades enormes de informações operando em redes globais (Dias, 2007): um meio técnico-científicoinformacional (Santos, 1994) ascende como característica fundamental do período atual.

Dessa maneira, conforme indica Raffestin (1993), é importante questionar quem controla a informação, quem a difunde, seus usos e seu papel na reestruturação da economia e do espaço. Segundo Dias (2007, p. 138):

Nesse aspecto, no território organizado em redes, alguns atores atuam com maior força que outros. Os atores que produzem e controlam as redes técnicas fazem com o objetivo de tornar a rede um instrumento de poder no território. Assim, os atores que têm o poder de construir e controlar as redes técnicas também passam a ter a possibilidade de controlar territórios.

Funcionando em complexas redes de interconexões, toma forma, segundo Mattelart (2001), uma informação organizacional ${ }^{3}$, a qual poucas e poderosas corporações têm acesso. Para Santos (1996, p. 147),

Controle centralizado e organização hierárquica conduzem à instalação de estruturas ineigualitárias, já que a informação essencial é exclusiva e apenas transita em circuitos restritos. Cerca de noventa por cento de todos os dados veiculados por meio de satélites o fazem entre grandes corporações e metade das mensagens transnacionais cabe dentro das redes de empresas multinacionais.

Tais informações, aliás, são fundadas em práticas científicas utilizadas para orientar análises de conjuntura e criar vantagens competitivas e são controladas por oligopólios de grandes empresas 
globais. São atividades ligadas à emergência do circuito superior da economia urbana ${ }^{4}$ e estão inseridas no setor quaternário da produção. O setor quaternário, segundo a definição de Tomelin (1988, p. 127),

é caracterizado pela ação de conceber, dirigir, controlar e transmitir através do entorno científico e técnico, confere a esses atos um valor econômico; sua atividade dominante é a criação. $\mathrm{O}$ ato linear do processo de decisão passa pela concepção, ou seja, é preciso primeiro conceber, deliberar, decidir, fazer executar e comunicar.

Uma das decorrências desse entrelaçamento da informação com o território foi o surgimento de um setor autônomo - de gerência relacionada à informação - que antes tinha suas ações definidas dentro das fábricas no regime fordista, mas que após a reestruturação produtiva são chamadas a diagnosticar tanto a economia quanto as regiões e os territórios, de maneira a articular as etapas da produção entre os espaços econômicos das formações socioespaciais. As plantas tayloristas/fordistas do início da industrialização são substituídas por uma produção em acumulação flexível $^{5}$, que compartimenta as plantas fabris em uma organização dispersa pelo território, especializando cada setor aos lugares, formando-se verdadeiros circuitos espaciais de produção em escala planetária (Figura 1).

Figura 1- Esquema das mudanças organizacionais da produção após a reestruturação produtiva e a revolução informacional
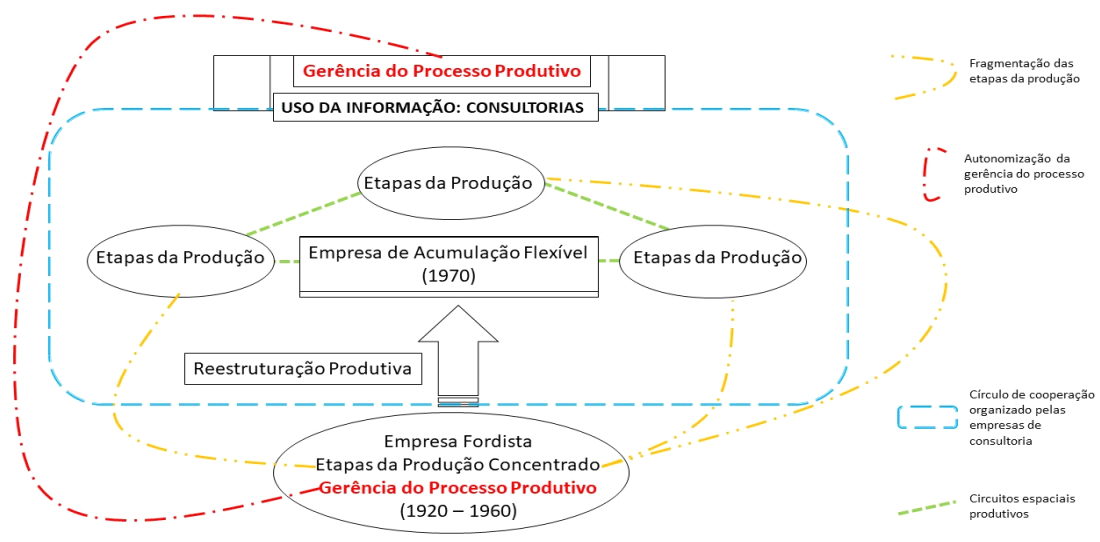

Fonte: Teixeira (2018). 
Assim, falamos das empresas de consultoria e auditoria que assumem a gerência do processo produtivo em nível planetário, o que nos autoriza a adjetivá-las como consultoras globais, responsáveis por coordenar as informações estratégicas para a operação dos círculos de cooperação entre as diversas empresas que compõem os circuitos espaciais produtivos. Trata-se de empresas que investigamos em trabalhos anteriores $^{6}$ e identificamos como verdadeiras empresas de informação, como preferimos denominá-las, relacionadas aos serviços de auditoria, consultoria e gerenciamento de banco de dados ${ }^{7}$.

Neste circuito, destacam-se as empresas globais de consultoria conhecidas como "Big Four" - PwC, KPMG, E\&Y e Deloitte - que controlam a maior parte do mercado de consultoria e auditoria do mundo, em conjunto com as empresas especializadas em estratégia empresarial ${ }^{8}$. Essas empresas controlam a maior parte do mercado mundial de serviços de consultoria e auditoria nas últimas décadas e estão associadas às mudanças gerenciais pelas quais passou o capitalismo a partir da década de 1970.

Temos, aqui, que retomar a ideia da importância crescente do gerente no processo de elaboração, organização e planejamento do processo produtivo. Dessa forma, o poder dos gerentes pode crescer de tal maneira que eles se tornarão firmas autônomas, conforme já demonstramos (rever Figura 1). Harvey ([1982] 2013, p. 214), analisando a estrutura mutante de desenvolvimento do capitalismo, observa que:

Pode haver também pouca dúvida de que a "classe gerencial" tenha até certo ponto assumido uma vida própria, se tornando relativamente autônoma dos donos do capital e, desse modo, se transformando em uma fonte de permanência, poder e crescimento contínuo.

Foram duas as vertentes fundamentais para o desenvolvimento da atuação das consultoras globais diante das transformações no modo de produção capitalista. Na primeira vertente, destaca-se o uso das empresas de consultoria para a reorganização das corporações no sentido da maior fragmentação das etapas produtivas pelo espaço. Dessa maneira, a dinâmica da reestruturação produtiva, inicialmente verificada na Europa e EUA - em conjunto com as mudanças gerenciais japonesas relacionadas ao toyotismo -, é o principal impulsionador do crescimento das consultorias.

A segunda vertente está ligada à participação das consultoras globais no planejamento territorial, sobretudo nos países subdesenvolvidos - nos 
quais há um mercado ainda em expansão desde o começo da década de 1990. Isso porque, nesses países, como é o caso do Brasil, as políticas neoliberais possibilitaram a entrada dessas empresas nos processos de privatizações em que tiveram o papel fundamental de organizar o processo de espoliação das infraestruturas públicas (Harvey, 2004) em favor das corporações privadas, tornando, assim, como assinala Vainer (2007), o planejamento territorial parte das estratégias corporativas.

Vemos, portanto, as articulações de objetos e ações que conformam o novo meio geográfico. De um lado, as mudanças no conjunto de técnicas de produção ancoradas na informação organizacional; do outro, e de forma imbricada, as ações dessas empresas de consultoria, sintetizadas em ideologias, discursos e normas. Essa também é a "cara” da globalização com seus novos conteúdos. As experiências de atuação em vários países credenciaram essas empresas para serem difusoras das ideologias e tecnologias globalizantes.

\section{A empresa de consultoria Deloitte e suas articulações no território brasileiro}

Dentre as empresas de consultoria no mundo, a Deloitte destaca-se por sua longa atuação no Brasil. É o que atesta Medeiros (2005, p. 15),

As firmas de auditoria provenientes dos países onde as bases do capitalismo já estavam sedimentadas (Estados Unidos da América do Norte e Inglaterra), abriram filiais no Brasil, logo nas primeiras décadas do século XX. Assim, a firma antecessora da atual multinacional Deloitte Touche Tohmatsu abriu seu primeiro escritório em solo brasileiro em 1911, na cidade do Rio de Janeiro (RJ), e um segundo na cidade de Recife (PE), em 1917.

As relações corporativas dessa empresa são diversas e poderosas e, por isso, são capazes de operacionalizar os sistemas técnicos e as normas para articular ações. Para auxiliar no entendimento de como se dá a relação entre consultora e empresas é preciso focalizar as funções das consultorias.

Primeiro, como ponto de partida, é importante notar que a Deloitte passou por intensos processos de fusões e aquisições em suas estruturas, o que levou às mudanças nas funções, passando a atuar em três categorias: i. arbitragem de disputas internas e externas às empresas; ii. produção e 
difusão de conceitos acerca do mundo empresarial e iii. implementação de mudanças organizacionais nas corporações.

Acrescentamos que essas mudanças operam mudanças espaciais nas estruturas das empresas. Seguindo esse rearranjo, a empresa Deloitte passou por sucessivas reorganizações e incorporações que possibilitaram ampliar os ganhos e articulações em escalas globais, como pode ser visto na Figura 2.

Figura 2 - Constituição histórica da Deloitte

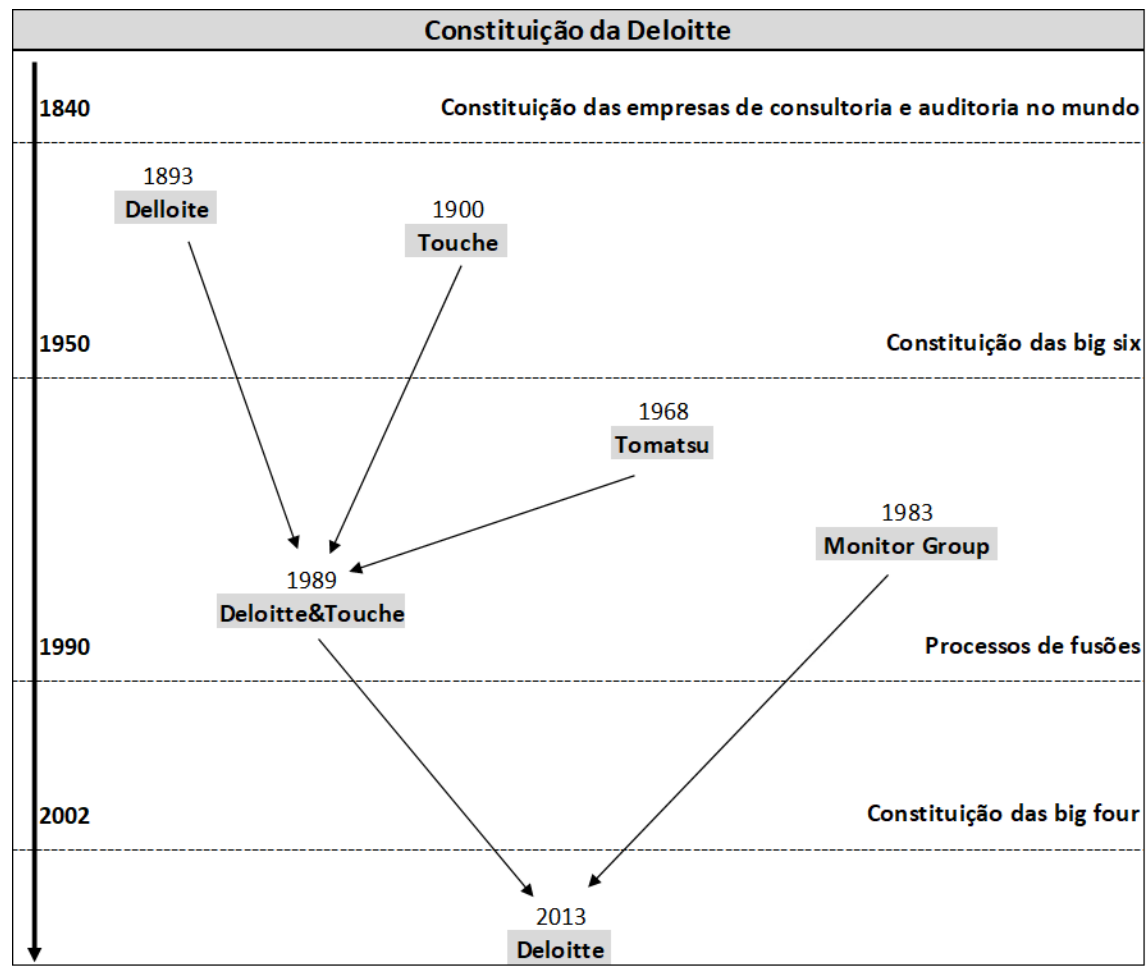

Fonte: Dados trabalhados por Teixeira (2018) com informações de Donadone (2001); Deloitte Global Report (2012-2-15); e do sítio eletrônico <http:/www2.deloitte.com.br>. Acesso em: 18 dez. 2018.

Soma-se a isto a enorme diversidade de setores atendidos pelos serviços dessa consultora, o que nos autoriza dizer que nenhum setor 
da economia opera, hoje, sem assessoria dessas grandes empresas de informação. A título de exemplo, o Quadro 1 a seguir mostra a estrutura de funcionamento e organização da consultoria Deloitte.

Quadro 1 - Topologia da consultoria Deloitte - 2018

\begin{tabular}{|c|c|c|c|c|}
\hline Fundação & $\begin{array}{c}\text { Escritórios } \\
\text { Brasil }\end{array}$ & Países & $\begin{array}{c}\text { Funcionários } \\
\text { Mundo }\end{array}$ & Atividades de consultoria \\
\hline 1911 & 12 & 155 & 225.000 & $\begin{array}{c}\text { Auditoria, Consultoria em gestão de riscos empresariais, } \\
\text { gestão de capital humano, consultoria empresarial, } \\
\text { consultoria tributária, finanças corporativas, serviços } \\
\text { financeiros, tecnologia, mídia e telecomunicações, } \\
\text { turismo, hotelaria e entretenimento, varejo e bens de } \\
\text { consumo }\end{array}$ \\
\hline
\end{tabular}

Fonte: Dados trabalhados pelos autores com informações do sítio eletrônico <https://www2.deloitte.com/br/pt.html > . Acesso em: 10 out. 2018.

Analisando o Quadro 1, confirma-se o que diversos autores (Donadone, 2003; Farias, 2008; Manzoni Neto; Silva, 2007; Manzoni Neto, 2007; Silva, 2001; Silva, 2009; entre outros) têm destacado: a importância das empresas de consultoria como fundamentais ao modus operandi do mercado capitalista atual.

Mencionamos, anteriormente, que a atuação das empresas de consultoria no Brasil não é recente. Entretanto, somente nas últimas décadas elas ganharam peso nas articulações do mercado nacionalinternacional, visto que tal processo também acompanhou e subsidiou os processos de privatização. Ao analisar o faturamento das "big four" no mundo, podemos confirmar essa hipótese, haja vista os ganhos de faturamento a partir da década de 1990 (Tabela 1). 
Tabela 1 - Comparativo de Receitas das Quatro Principais Consultoras do Mundo em 1996, 2009 e 2015

\begin{tabular}{|c|c|c|c|c|c|c|c|c|}
\hline \multicolumn{4}{|c|}{ Consultorias em 1996 } & \multicolumn{3}{c|}{ Consultorias em 2009 } & \multicolumn{3}{c|}{ Consultorias em 2015} \\
\hline Empresas & $\begin{array}{c}\text { Receitas } \\
\text { (S\$ } \\
\text { Bilhões) }\end{array}$ & Funcionários & Empresas & $\begin{array}{c}\text { Receitas } \\
\text { (S\$ } \\
\text { Bilhões) }\end{array}$ & Funcionários & Empresas & $\begin{array}{c}\text { Receitas } \\
\text { (S\$ } \\
\text { Bilhões) }\end{array}$ & Funcionários \\
\hline $\begin{array}{c}\text { Andersen } \\
\text { Consulting }\end{array}$ & 5,3 & 45.000 & PrwC & 26,2 & 163.000 & PwC & 35,4 & 208.000 \\
\hline $\begin{array}{c}\text { Ernst \& } \\
\text { Young }\end{array}$ & 3,5 & 11.200 & Delloitte & 26 & 169.000 & Delloitte & 35,2 & 225.000 \\
\hline $\begin{array}{c}\text { Coopers \& } \\
\text { Lybrand }\end{array}$ & 2,9 & 9.000 & $\begin{array}{c}\text { Ernst \& } \\
\text { Young }\end{array}$ & 21,4 & 144.441 & E\&Y & 28,4 & 212.000 \\
\hline $\begin{array}{c}\text { Mckinsey\& } \\
\text { Co }\end{array}$ & 2,9 & 3.900 & KPMG & 22,7 & 135.000 & KPMG & 24,4 & 173.000 \\
\hline Total & 14,6 & 69.100 & Total & 96,3 & 611.441 & Total & 123,4 & 818.000 \\
\hline
\end{tabular}

Fonte: Dados trabalhados por Silva (2017) com informações de Donadone (2001); KPMG International Annual Review (20102015); Delloite Global Report (2012-2015); PwC Global Annual Review (2010-2015) e E\&Y Global Review (2010-2015).

Entre os anos de 1996 a 2009 as empresas de consultoria tiveram um crescimento vertiginoso. As receitas contabilizadas das quatro principais consultoras em 1996 contabilizam cerca de US\$ 14 bilhões; já em 2009, as quatro primeiras operam com receitas de mais de US\$ 96 bilhões. Destaca-se que mudanças importantes acontecem no setor, se verificadas as empresas que assumem os patamares mais altos e que passam por processos de fusões e aquisições para alavancagem dentro do mercado.

A hipótese de alavancagem de seus rendimentos estarem associados à entrada nos países subdesenvolvidos confirma-se ao verificar a Tabela 1. São as empresas líderes das "big four" que operam esse crescimento e o fazem a partir do domínio sobre situações geográficas de países subdesenvolvidos, sendo financiadas por grandes empresas. No caso do Brasil bancos estatais, em especial o Banco Nacional de Desenvolvimento Econômico e social (BNDES) ${ }^{9}$.

Em 2015, o rendimento dessas empresas chegou ao total de $\$$ 123 bilhões. O número de funcionários também é, em grande medida, definidor das ações dessas empresas. O total de funcionários passou de 69.100 em 1996, para 818.000 em 2015. O número é relevante pois se trata de funcionários dos mais altos escalóes empresariais, formados em grandes universidades internacionais e com forte poder difusor da ideologia dominante sobre os diversos tipos de planejamento corporativo ${ }^{10}$. 
Chamadas a gerenciar as privatizações e substituir parte das ações do Estado no planejamento territorial, essas empresas administram setores e segmentos a custos bilionários. Observe a seguir, no Quadro 2, o levantamento feito em nossas pesquisas sobre as empresas que foram clientes da Deloitte no Brasil no ano de 2017 e suas respectivas receitas.

Quadro 2 - Ativos das Empresas Clientes da Deloitte no Brasil por Setor (Ativo Total - R\$ - mil)

\begin{tabular}{|c|c|}
\hline \multicolumn{2}{|l|}{ Transporte } \\
\hline $\begin{array}{l}\text { Ferrovia Transnordestina Logística S.A. (FTL), CCR S.A., Investimentos e Participações } \\
\text { em Infraestrutura S.A. (Invepar), Gol Linhas Aéreas Inteligentes S.A., Ecorodovias } \\
\text { Infraestrutura e Logística S.A.., Ecorodovias Concessões e Serviços S.A., Transnordestina } \\
\text { Logística S.A. (TLSA), Concessionária do Sistema Anhanguera-Bandeirantes S.A. } \\
\text { (AutoBan), Hidrovias do Brasil S.A., Ferrovia Norte-Sul S.A. (FNS), Concessionária Auto } \\
\text { Raposo Tavares S.A. (CART), Rodovia das Colinas S.A., Autopista Fluminense S.A., } \\
\text { Autopista Fernão Dias S.A., Concessionária Rodovias do Tietê S.A., Autopista Planalto } \\
\text { Sul S.A., Triângulo do Sol Auto-Estradas S.A., WLM Indústria e Comércio S.A., Salus } \\
\text { Infraestrutura Portuária S.A.,, Centrovias - Sistemas Rodoviários S.A., Vivax S.A. }\end{array}$ & $646.330 .221,00$ \\
\hline \multicolumn{2}{|l|}{ Serviços Financeiros } \\
\hline $\begin{array}{l}\text { Cielo S.A., Gaia Agro Securitizadora S.A., Porto Seguro S.A., Sul América S.A., Tarpon } \\
\text { Investimentos S.A., Safra Leasing S.A. Arrendamento Mercantil, Sonae Sierra Brasil } \\
\text { S.A., Sonae Sierra Brasil S.A., São Carlos Empreendimentos e Participações S.A., Valid } \\
\text { Soluções e Serviços de Segurança em Meios de Pagamento e Identificação S.A., Tarpon } \\
\text { Investimentos S.A., Nova Ação Participações S.A., Gaia Securitizadora S.A., Gaia Agro } \\
\text { Securitizadora S.A. }\end{array}$ & $171.244 .227,00$ \\
\hline \multicolumn{2}{|l|}{ Energia e Mineração } \\
\hline $\begin{array}{l}\text { Cia Energética de Minas Gerais (Cemig), Companhia Paranaense de Energia (Copel), Engie } \\
\text { Brasil Energia S.A., Cemig Distribuição S.A., Cemig Geração e Transmissão S.A., Light } \\
\text { Serviços de Eletricidade S.A., Centrais Elétricas de Santa Catarina S.A. (Celesc), Renova } \\
\text { Eólica Participações S.A., Energisa Mato Grosso do Sul - Distribuidora de Energia S.A., Cia } \\
\text { de Ferro Ligas da Bahia (Ferbasa), Priner Serviços Industriais S.A. }\end{array}$ & $157.512 .513,00$ \\
\hline \multicolumn{2}{|l|}{ Consumo e Varejo } \\
\hline $\begin{array}{l}\text { Localiza Rent A Car S.A., Biosev S.A., Springs Global Participações S.A., Tecnisa S.A., } \\
\text { Terra Santa Agro S.A., Smartfit Escola de Ginástica e Dança S.A., International Meal } \\
\text { Company Alimentação S.A. (IMC), Cia Tecidos Santanense, Sauipe S.A., Taipe Trancoso } \\
\text { Empreendimentos S.A. }\end{array}$ & $30.877 .037,00$ \\
\hline \multicolumn{2}{|l|}{ Máquinas, Equipamentos, Papel e Celulose } \\
\hline Weg S.A., Duratex S.A., Celulose Irani S.A., Metalfrio Solutions S.A., Kepler Weber S.A. & $27.051 .390,00$ \\
\hline \multicolumn{2}{|l|}{ Construção e Incorporação } \\
\hline $\begin{array}{l}\text { Arteris S.A., EZTEC Empreendimentos e Participações S.A., Construtora Adolpho } \\
\text { Lindenberg S.A. (Grupo LDI), Eternit S.A. }\end{array}$ & $16.533 .521,00$ \\
\hline \multicolumn{2}{|l|}{ Tecnologia, Mídia e Telecomunicações } \\
\hline Abril S.A., Positivo Informática S.A., Cemig Telecomunicações S.A. & $5.730 .961,00$ \\
\hline
\end{tabular}


Farmacêutico, Hospitalar e Químico

\begin{tabular}{|c|c|}
\hline Unipar Carbocloro S.A., Instituto Hermes Pardini S.A. & $4.699 .281,00$ \\
\hline \multicolumn{2}{|l|}{ Agronegócio } \\
\hline Companhia Mineira de Açucar e Álcool Participações S.A. (CMAA) & $1.053 .300,00$ \\
\hline Total & $1.061 .032 .451,00$ \\
\hline
\end{tabular}

Fonte: Dados trabalhados por Teixeira (2018) com informações da Bovespa, do Site Econoinfo e Comissão de Valores Mobiliários (CVM) para 0 ano de 2017.

Entre os clientes da empresa estão as maiores corporações atuantes no Brasil, destacando-se as empresas Cielo, Companhia Siderúrgica Nacional, CEMIG e CPFL. Todas com patrimônios superiores a 40 bilhões de reais. Somados, os valores patrimoniais das empresas clientes da Deloitte no Brasil ultrapassam a marca de 1 trilhão de reais.

Podemos, assim, inferir com segurança três motivos principais que tornam as empresas de consultoria fundamentais no planejamento corporativo brasileiro. Primeiro, são detentoras de bancos de dados sobre o uso e a produção do território. Segundo, participam das tomadas de decisões sobre as infraestruturas territoriais que operaram o planejamento territorial durante décadas do desenvolvimentismo e, por isso, são donas de imensas articulações territoriais. Terceiro, operam e organizam as contas de gigantes corporações globais sendo responsáveis por enormes somas de patrimônio. Faremos, agora, uma breve análise da topologia dos escritórios da consultora global Deloitte, observando as articulações dela com a rede urbana.

Rede urbana e empresas de consultoria

A função de gerência atribuída ao papel da informação organizacional permitiu, como assinalou Lencioni (2008), a desconcentração das indústrias no território brasileiro e a centralização do comando da produção nos espaços polarizados da rede de cidades. Autonomia e interdependência, dispersão e concentração são processos que se aprofundaram e mudaram a forma de relacionamento do planejamento do Estado e das corporações. Essas últimas adentraram os países subdesenvolvidos, instalando seus escritórios nos principais centros de gestão do território (Corrêa, 2006).

Para demonstrar como as empresas de consultoria escolhem, seletivamente, os lugares onde se instalam, tomamos por base a 
classificação da rede de cidades por regiões de influências (IBGE, 2008). Isso, pois, as variáveis-chave escolhidas pelas empresas de consultoria, ao instalarem seus escritórios, levam em consideração $a$ densidade, $a$ topologia e a configuração hierárquica da rede de cidades. Dessa maneira, as redes de escritório das consultoras utilizam-se das relações que são definidas entre os núcleos urbanos, o território e o sistema urbanoregional (Egler, 2002). Fazendo uso das densidades (sejam técnicas e/ou informacionais), as corporações organizam os próprios escritórios segundo a lógica da rede urbana (Santos, 1996; Santos; Silveira, 2001).

Analisando os mapas de fluxos de gestão no território (Mapa 1) e topologia dos escritórios da consultora Deloitte no Brasil ${ }^{11}$ (Mapa 2), evidenciamos com nitidez a relação entre os fixos (escritórios) e os fluxos informacionais (comandos de gestão). Os escritórios distribuem-se pelas principais cidades do país, sendo nove deles na Região Concentrada do território $^{12}$ (quatro no estado de São Paulo, sendo dois escritórios na cidade de São Paulo). Em São Paulo, os escritórios da empresa encontram-se em nós dinâmicos da rede urbana paulista, com pontos de maior hierarquia de comando: São Paulo (Grande Metrópole Nacional), Campinas (Capital Regional A) e Ribeirão Preto (Capital Regional A) ${ }^{13}$.

Todas essas cidades são preparadas para receber o aporte informacional da empresa, que se instala segundo os atributos informacionais presentes nas famílias de objetos dessas localidades, tais como universidades de ponta, setor de serviços diversificados e modernizados e setor produtivo de alta tecnologia. Levantamos a hipótese de uma relação estreita e não casual entre a localização dos escritórios da empresa e os nós mais dinâmicos (e articuladores) da rede urbana. Isso porque esses lugares configurar-se-iam como espaços privilegiados para conformação e comando dos círculos de cooperação no território: um espaço de fluxos reguladores.

Nessa verdadeira arquitetura urbano-informacional chama a atenção o papel da região concentrada, que abarca oito escritórios da consultora, evidenciando a heterogeneidade de comando e de densidade técnica entre as regiões brasileiras e a função de comando da região concentrada, alavancada pelo processo de desconcentração da indústria de São Paulo e centralização do comando na capital paulista. 
Mapa 1 - Brasil: Fluxos de Comando e Gestão do Território

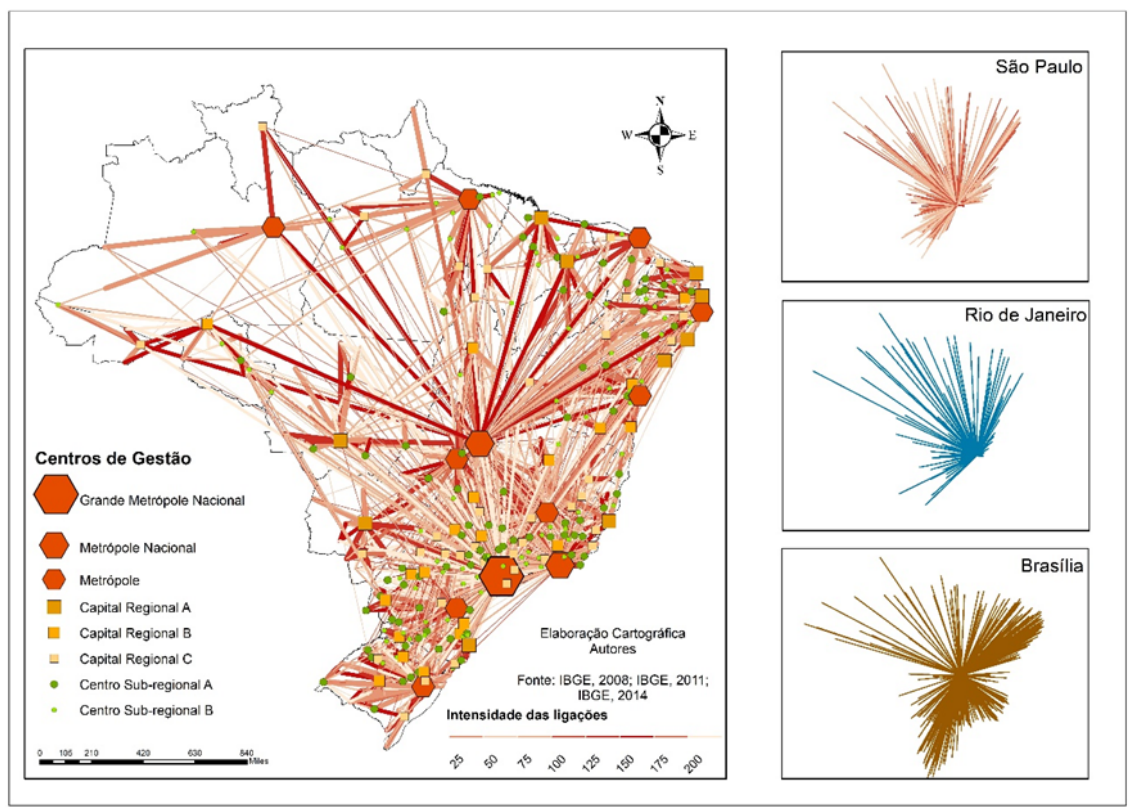

Fonte: Dados elaborados por Sérgio Teixeira (2018) com informações de IBGE (2008, 2011, 2014). 
Map 2 - Brasil: Topologia dos escritórios da Consultora Deloitte em 2018

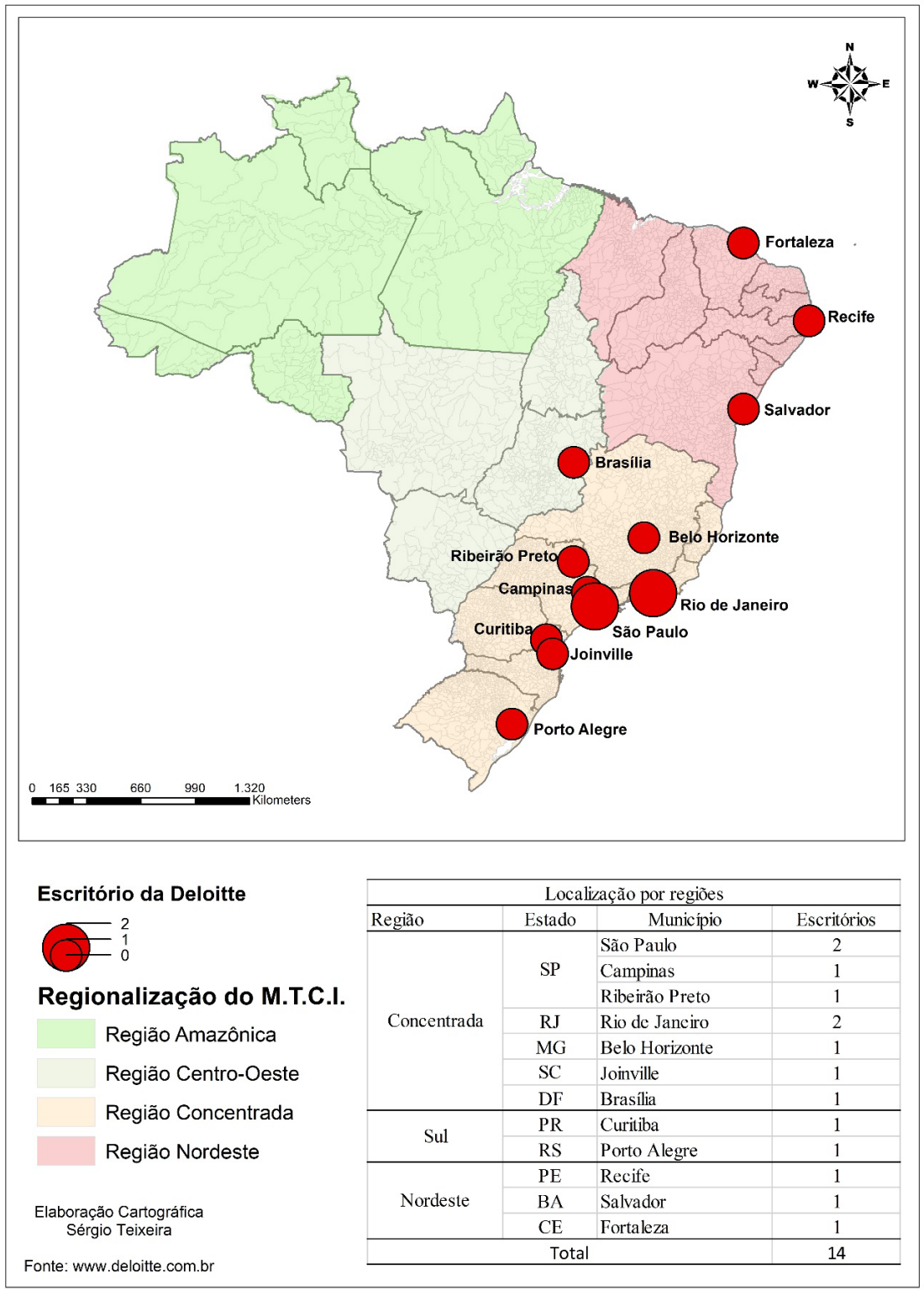

Fonte: Dados trabalhados por Silva (2018) com informações do sítio eletrônico <www.deloitte.com.br>. Acesso em: 10 dez. 2018. 
A Região Metropolitana de São Paulo passou, assim, por um processo de expansão da indústria e, posteriormente, em um período mais recente, a uma desconcentração industrial, no sentido de uma expansão do dinamismo da cidade de São Paulo para outras cidades da região metropolitana. Ao mesmo tempo, o que se verifica é uma concentração dos serviços avançados ligados ao setor quaternário na capital paulista.

Para Lencioni (2004, p. 70)

Trata-se de um processo de expansão da concentração, de um processo de desconcentração territorial da indústria da região metropolitana, no qual a cidade de São Paulo afirma e desenvolve sua centralidade, se inserindo como um nó da rede mundial de cidades globais. Tanto que os serviços especializados relativos às finanças, à propaganda, ao marketing, ao planejamento e à consultoria tendem a se concentrarem na capital.

Abrigando os serviços mais avançados dos serviços superiores da economia urbana (SANTOS, [1979] 2007; SILVA, 2002) ligados à informação, a cidade de São Paulo desenvolverá sua centralidade ${ }^{14}$, tornando-se o principal centro de gestão do território, em conjunto com o Rio de Janeiro (RJ) e Brasília (DF), tornar-se-á importante nó da rede mundial de cidades.

As grandes empresas de consultoria, configuradas dentro desses circuitos informacionais, têm em São Paulo abrigo para se desenvolver. Como já destacamos, o setor quaternário da economia espacializa-se em lugares onde as rugosidades, materializadas em uma base técnica (uma tecnosfera), apresentam maior desenvolvimento.

O rompimento das múltiplas ordens locais com a mundialização do capitalismo forjou um planeta em reconstrução permanente. Plásticas, as redes globais seguem sua trama em busca de lucro e à custa de uma quantidade infinita de informações. Os territórios onde se instalam são objetos de exímia avaliação sendo, em seguida, convidados a uma informatização na forma de novos objetos e novas ações (Teixeira; Silva, 2011).

Frise-se que este processo se dá de forma vertical, é hierárquico. Portanto, a concentração dos serviços superiores da economia urbana das grandes empresas de consultoria na cidade de São Paulo é fruto do papel de comando da cidade na rede de cidades do território brasileiro. É por meio da concentração técnica, situada na capital paulista, que as ordens se dão para o restante do território. Isso porque o meio técnico-científico- 
informacional não se instala em todos os lugares, ainda que comande todo o território. Os fluxos de informação, com seu poder articulador, acabam por moldar as áreas de influências das cidades.

A informação e as empresas de consultoria impulsionam mudanças substanciais na divisão técnica, social e territorial do trabalho contemporâneo, contribuindo para transformar as regiões em que atuam em pontos luminosos das redes corporativas globalizadas.

\section{Considerações finais}

Discutimos que as empresas de consultoria são, hoje, detentoras de informações estratégicas que as dotam de poder e articulação territorial, possibilitando-as impor as racionalidades da globalização ao território de forma vertical e hierárquica.

Dois eixos fundamentais foram estruturantes no processo de formação do mercado de empresas de consultoria. Um primeiro eixo esteve relacionado às mudanças organizacionais que são endógenas ao capitalismo desde seu surgimento e disparam sucessivos processos de reorganização, sobretudo, mas não apenas, em momentos de crise. As empresas de consultoria nasceram desse processo como externalidades às atividades bancárias e passaram, por meio de novas regulações relacionadas às normas que operacionalizaram a estrutura organizacional dos bancos, a integrar o escopo de atividades financeiras relacionadas às análises de desempenho, verificação de contas e reestruturação empresarial.

O segundo eixo de desenvolvimento das empresas de consultoria foi sua entrada nos países subdesenvolvidos, por meio do que Santos ([1979] 2007) identificou como um planejamento da pobreza e da desigualdade.

Sem o planejamento teria sido impossível atingir-se uma intromissão tão rápida e brutal do grande capital nessas nações. Não cremos que seja exagero afirmar que o planejamento tem sido instrumento indispensável à manutenção e ao agravamento do atraso dos países pobres, assim como ao agravamento ou à exacerbação de disparidades sociais (SANTOS, [1979] 2007 p. 13).

Foi por meio da intensificação dos processos de neoliberalização e privatizações que, a partir da década de 1990, as consultoras aprofundaram a atuação no território nacional mediante o planejamento 
das infraestruturas territoriais que foram espoliadas. Para Vainer (2007, p. 5), esse processo foi fundamental para decretar o fim do planejamento Estatal, haja vista que "a privatização dos setores responsáveis pela infraestrutura acabou tendo como corolário a privatização dos processos de planejamento e controle territorial que são intrínsecos aos grandes projetos".

Procuramos demonstrar, por meio da análise da atuação consultora global Deloitte no Brasil, que a decorrência desse processo foi um aprofundamento do controle do planejamento territorial pelas empresas de consultoria que se tornaram gigantescas corporações responsáveis por organizar as contas das maiores corporações no Brasil e se utilizaram das fragmentações da rede urbana para o ganho de escala de suas ações no território.

No Brasil, essas grandes empresas têm cada vez mais ganhos a partir do processo de espoliação das infraestruturas territoriais e conseguiram com isso alavancar o poder sobre o território a partir de um uso corporativo da rede de cidades, que possibilitou ganhos de escala e know hall para atuar na reorganização das empresas.

Articulando os serviços de consultoria e auditoria com o território e detendo informações sobre os sistemas de engenharia de grande porte, elas, hoje, fazem parte do que defendemos como um novo planejamento em ascendência, em grande escala, que identificamos como um planejamento corporativo do território.

\section{Notas}

1 Circuitos espaciais de produção "são definidos pela circulação de bens e produtos e, por isso, oferecem uma visão dinâmica, apontando a maneira como os fluxos perpassam o território" (Santos; Silveira, 2001, p. 143). Os círculos de cooperação tratam da comunicação das ordens e das informações (fluxos imateriais) necessárias aos circuitos espaciais produtivos, garantindo a organização de agentes dispersos geograficamente. Dessa maneira, concordamos com Santos (1988 p. 50) quando afirma que a análise dos circuitos espaciais de produção "junto com a dos círculos de cooperação nos dá a organização local e sua posição na hierarquia do poder mundial. Discutir os circuitos espaciais de produção - distribuição-troca-consumo como movimento circular constante. Captar seus elementos determinantes é dar conta da essência de seu movimento".

2 No intuito de identificar as novas articulações da informação no período pósreestruturação produtiva, surgiram diversas teses que buscaram defender a ascendência da informação como o motor do desenvolvimento do capitalismo em uma suposta sociedade pós-industrial baseada na supremacia da comunicação e da informação. 
Entre essas, destacaram-se as teses da sociedade pós-industrial (Bell, 1978), da sociedade informacional (Lyotard,1986), da sociedade da informação (Castells, 1999) e da hegemonia da esfera comunicacional (Habermas, 1982). Concordamos com a crítica levantada por Lojkine (1995), Antunes (1999) e Mattelart (2001), para os quais aqueles autores esquecem-se de analisar que a informação, ainda que relevante na articulação da produção, tem o papel de articular a organização da produção material, que tem como base a produção e o território, não atuando de forma autônoma.

3 Segundo Mattelart (2001), para a articulação da produção as empresas não fazem uso de uma informação banal, aquela a que todos têm, potencialmente, acesso ilimitado. Enfocamos, concordando com o autor, a informação organizacional, a qual poucas empresas e poucos Estados acessam, exatamente por serem estratégicas à acumulação, ao poder e ao controle do uso do território. Para Silva (2002), trata-se de uma informação produtiva.

4 Segundo Santos ([1979] 2004), existem dois subsistemas na organização do espaço dos países subdesenvolvidos, ambos decorrentes das modernizações tecnológicas: "O circuito superior é resultado direto da modernização tecnológica e seus elementos mais representativos são os monopólios. A maior parte de suas relações ocorrem fora da cidade e da área que a circunda porque este circuito tem um quadro de referência nacional ou internacional. O circuito inferior consiste de atividades em pequena escala e diz respeito à população pobre" (Santos, [1979] 2004, p. 126).

5 "Tentando reter seus traços constitutivos mais gerais, é possível dizer que o padrão de acumulação flexível articula um conjunto de elementos de continuidade e descontinuidade que acabam por conformar algo relativamente distinto do padrão taylorista/fordista de acumulação. Ele se fundamenta num padrão produtivo organizacional e tecnologicamente avançado, resultado da introdução de técnicas de gestão da força de trabalho próprias da fase informacional, bem como da introdução ampliada dos computadores no processo produtivo e de serviços" (Antunes, 1999, p. 52).

6 Para uma consulta a esses trabalhos em que identificamos e depuramos a relação entre as empresas de consultoria e o uso do território ver Silva (2009; 2012), Silva e Farias (2008), Manzoni Neto (2008) e Teixeira e Silva (2011).

7 "Os bancos de informação constituem sobretudo um dado constitutivo do tempo, na medida em que sua utilização permite uma nova aceleração. Alvo de uma atualização contínua, elas são organizadas por empresas de informação, como as editoras de revistas especializadas de economia, institutos privados de pesquisa, firmas de consultoria e empresas de informação nacionais e globais. Formas de organização social, essas empresas configuram aquilo que P. Claval (1993, p. 160) denomina sistema de comunicação, cuja função é colher, guardar e elaborar as informações para utilizá-las no momento das decisões" (Silveira, 1999, p. 208).

8 Neste artigo damos ênfase às empresas que controlam o mercado de consultorias e auditorias. Essas empresas são conhecidas como acconting firms e são responsáveis por organizar a auditar as mais importantes empresas dos círculos de cooperação globais. Entretanto, devemos destacar que nos últimos anos, segundo Donadone (2001), Silva (2001), Manzoni Neto (2007) e Teixeira e Silva (2011), as empresas de consultoria especializadas em estratégia despontaram no mercado ao elaborarem estratégias de novas formas de estrutura organizacional, performance financeira e normatizações para grandes empresas e para o Estado. 
9 Uma análise detida do relacionamento das empresas de consultoria com o BNDES foi feita em Farias (2008) e Silva e Farias (2008).

10 Vainer (2007) destaca o papel das escolas dos consultores nas estratégias de planejamento ao destacar a difusão do planejamento estratégico. "A adesão de Castells apenas ilustra um movimento intelectual que, ao longo dos anos 1990, conferiria à palavra estratégia e à expressão planejamento estratégico lugar de honra no jargão dos planejadores. Em um primeiro momento, Sun Tzu, Clausewitz e outros menos votados foram importados das escolas militares para as escolas de business, em primeiro lugar a escola-líder - a Harvard Business School. Em seguida, com os devidos cuidados e adaptações, foram conduzidos às escolas e práticas de planejamento regional e urbano" (Vainer, 2007, p. 18).

11 No Brasil, a consultora conta com cerca de 5.500 funcionários que atuam em diversos serviços (auditoria, consultoria, contábil, fusões, aquisições, consultoria tributária e educação empresarial), de inúmeras áreas corporativas (bens de consumo e produtos industriais, energia [óleo, gás e mineração], serviços financeiros, seguros, tecnologia, mídia, telecomunicações e setor público).

12 Para Santos (1994), a região concentrada coincide com a área contínua de manifestação do meio técnico-científico-informacional, ao passo que nas demais regiões do país tal manifestação ocorre de maneira seletiva e pontual.

13 Classificação segundo a Região de Influência de Cidades (IBGE, 2008).

14 "A principal contribuição do conceito de centralização para a interpretação do urbano é que a gestão empresarial dos grupos econômicos e das grandes empresas em rede priorizam a metrópole e, no caso brasileiro, prioriza a metrópole de São Paulo. É no exercício da função central da metrópole, que é de controle do capital, que se adensam os serviços produtivos, os serviços voltados às empresas, muitas vezes denominados de serviços avançados" (Lencioni, 2008, p.14).

\section{Referências}

ANTUNES, R. Os sentidos do trabalho. São Paulo: Boitempo Editorial, 1999.

BELL, D. O advento da sociedade industrial: uma tentativa de previsão social. São Paulo: Cultrix, 1978.

BENKO, G. Economia, espaço e globalização na aurora do século XXI. São Paulo: Hucitec, 1996.

BRAVERMAN, H. Trabalho e capital monopolista: a degradação do trabalho no século XX. Rio de Janeiro: Editora Guanabara, 1987.

CASTELLS, M. A sociedade em rede. São Paulo: Paz e Terra, 1999.

CASTILLO, R. Sistemas orbitais e uso do território: integração eletrônica e conhecimento digital do território brasileiro. 1999. Tese (Doutorado) - Faculdade de Filosofia Letras e Ciências Humanas, Universidade de São Paulo, São Paulo,1999.

CORREAA, R. L. Estudo sobre a rede urbana. Rio de Janeiro: Bertrand Brasil, 2006.

DIAS, L. C. Redes de Informação, grandes organizações e ritmos de modernização. Revista etc.., espaço, tempo e crítica, v. 1, n. 2, jul. 2007. 
DONADONE, J. C. O mercado internacional de consultorias nas últimas décadas: crescimento, diversificação e formas de disputa. Caderno de pesquisa em administração, v. 10, n. 2, p. 1-15, 2003.

. Os Hunos já chegaram! Dinâmica organizacional, difusão de conceitos gerenciais e a atuação das consultorias. 2001. Tese (Doutorado) - Departamento de Engenharia de Produção, Universidade de São Paulo, São Paulo, 2001.

DANIELS, Peter. W. Service industries in the world economy. Blackwell, Oxford/ Cambridge, 1993.

EGLER, C. A. G.; MONIÉ, F. Urbanização Mundial e no Brasil: mudanças recentes e perspectivas. In: IPEA/IBGE/UNICAMP. (Org.). Estudos básicos para a caracterização da rede urbana no Brasil. Brasília: IPEA, v. 2, p. 319-343, 2002.

GALLOUJ, Faiz "Les Déterminants de L'Innovation dans les Activités de Conseil”. Revue Française du Marketing, no 149, 1994, pp. 33-51.

GALLOUJ, Faiz. Les services: une économie de la performance et de l'innovation. In: https://halshs.archives-ouvertes.fr/halshs-01116589, 2015.

HABERMAS, G. Conhecimento e interesse. Rio de Janeiro: Zahar, 1982.

HARVEY, David. O novo imperialismo. São Paulo: Loyola, 2004.

. A produção capitalista do espaço. São Paulo: Annablume, 2005.

. [1982]. Os limites do capital. São Paulo: Boitempo Editorial, 2013.

HEPWORTH, M. E. Geography of the information economy. Belhaven Press, London, 1989.

IBGE. Instituto Brasileiro de Geografia e Estatística. Região de Influência de Cidades 2007. Rio de Janeiro: IBGE, 2008.

LENCIONI, S. Novos rumos e tendências da urbanização e a industrialização no estado de São Paulo. In: LIMONAD (Org.). Brasil século XX: por uma nova regionalização. São Paulo: Max Limonad, 2004. p. 67-77.

. Concentração e centralização das atividades urbanas: uma perspectiva multiescalar Revista de Geografia Norte Grande, n. 39, p. 7-20, 2008.

LYOTARD, J. F. O pós-moderno. Rio de Janeiro: J. Olympio, 1986.

LOJKINE, J. A revolução informacional. São Paulo: Cortez, 1995.

MANZONI NETO, A. O novo planejamento territorial: empresas transnacionais de consultoria, parcerias público-privadas e o uso do território brasileiro. 2007. Tese (Doutorado) - Instituto de Geociências, Universidade Estadual de Campinas, 2007.

MARX, K. O Capital: crítica da economia política. São Paulo: Editora Abril, 1983.

MATTELART, A. Comunicação mundo: história das ideias e das estratégias. Rio de Janeiro: Editora Vozes, 2001.

MEDEIROS, E. S. de. A atividade de auditoria independente: um breve estudo sobre a independência dos auditores e as normas profissionais aplicáveis. 
2005. Monografia (Trabalho de Conclusão de Curso) - Instituto de Economia, Universidade Federal do Rio de Janeiro, Rio de Janeiro, 2005.

MONTEIRO, C. M. G. O planejamento: algumas considerações. Etc., espaço, tempo e crítica, v. 2, n. 1, p. 40-54, 2007.

RAFFESTIN, C. Por uma geografia do poder. São Paulo: Ática, 1993.

SANTOS, M. O retorno do território. In: SANTOS, M.; SOUZA, M. A. A. de; SILVEIRA, M. L. (Org.) Território: globalização e fragmentação. São Paulo: Hucitec; Anpur, 1994. p. 15-20. A natureza do espaço. São Paulo: Hucitec, 1996.

[1979] $O$ espaço dividido: os dois circuitos da economia urbana dos países subdesenvolvidos. São Paulo: Edusp, 2004. . [1993] A urbanização brasileira. São Paulo: Edusp, 2005.

$\overline{2} \overline{0} \overline{7}$. [1979] Economia Espacial: críticas e alternativas. São Paulo: Edusp, . [1988] Metamorfoses do espaço habitado. São Paulo: Edusp, 2008. [1994] Por uma economia política da cidade. São Paulo: Edusp, 2000. SANTOS, M.; SILVEIRA, M. L. O Brasil: território e sociedade no século XXI. Rio de Janeiro: Record, 2001.

SILVA, A. M. B. São Paulo, produção de informações e reorganização do território brasileiro. 2002. Tese (Doutorado) - Departamento de Geografia, Universidade de São Paulo, 2002.

. Círculos globais de informações e uso corporativo do território brasileiro: privatizações e planejamento territorial a partir dos anos 1990. Cadernos IPPUR/ UFRJ, v. XXIII, p. 09-32, 2009.

. Círculos de informações, urbanização e usos do território brasileiro. Revista da ANPEGE, v. 8, p. 3-15, 2012.

SILVA, A. M. B.; FARIAS, H. C. O BNDES e as empresas de consultoria na reorganização do território brasileiro na década de 1990. Redes, Santa Cruz do Sul, v. 13, p. 99-120, 2008.

SILVA, A. M. B.; MANZONI NETO, A. O Planejamento territorial no Brasil nos anos 1990: as ações das empresas globais de consultoria (o caso da empresa Booz-Allen \& Hamilton). GEOgraphia (UFF), v. 10, p. 1-23, 2008.

SILVA, A. M. B.; FARIAS, H. C. O BNDES e as empresas de consultoria na reorganização do território brasileiro na década de 1990. Redes, Santa Cruz do Sul, v. 13, p. 99-120, 2008.

TEIXEIRA, S. H. O. Planejamento corporativo e concessão aeroportuária no Brasil. Mercator, v. 17, p. 1-15. 2018.

TEIXEIRA, S. H. O.; SILVA A. M. B. Os usos das informações estratégicas sobre o território: a empresa de consultoria PriceWaterHousoCoopers e o planejamento territorial. Revista Brasileira de Estudos Urbanos e Regionais, v. 13, n. 2, p. 7187, 2011. 
TOURÉ, A. L. Services aux entreprises et espace intra-urbain: les relations face-àface et leur influence dans le comportement spatial des entreprises de servicesconseils em gestion. Doctorat em Etudes Urbaines. UQÀM, Montréal. 2010.

TOMELIN, M. O quaternário: seu espaço e poder. Brasília: Editora da UNB, 1988. VAINER, C. B. Planejamento territorial e projeto nacional. Revista Brasileira de Estudos Urbanos e Regionais (REBEURB), v. 9, n. 1, p. 9-23, 2007.

WOOD, Peter A. "Business services, the management of change and regional development in the UK". Transaction of the Institute of British Geographers, v. 21 (4). 1996, pp. 644-665.

Sérgio Henrique de Oliveira Teixeira - Graduado em Geografia pela Universidade Estadual de Campinas. Mestre e Doutor em Geografia pela mesma Universidade. Atualmente é docente do Curso de Licenciatura em Geografia e do Curso de Tecnologia em Gestão Ambiental do Instituto Federal de Educação, Ciência e Tecnologia do Sul de Minas Gerais - Campus Poços de Caldas. ID ORCID: https://orcid.org/0000-0001-8044-7854

Adriana Maria Bernardes Silva - Graduada em Geografia pela Universidade de São Paulo. Doutora em Geografia Humana pela mesma Universidade. Atualmente é docente do Curso de Bacharelado e Licenciatura em Geografia e da Pós-Graduação em Geografia da Universidade Estadual de Campinas. (iD) ORCID: https://orcid.org/0000-0003-4293-0460

\section{Contribuições dos autores}

Os autores ofereceram substanciais contribuições científicas e intelectuais ao estudo. As tarefas de preparação e redação do manuscrito, bem como revisão crítica, foram realizadas por ambos. O Autor Sérgio Henrique de Oliveira Teixeira ficou responsável pelo desenvolvimento teórico-conceitual inicial; por sua vez, a autora Adriana Maria Bernardes da Silva realizou acréscimos e correções fundamentais a partir de sua experiência de pesquisa. O texto final expressa um trabalho coletivo, realizado em especial como resultado da Tese de Doutoramento do autor Sérgio Henrique de Oliveira Teixeira, sob orientação da professora e autora Adriana Maria Bernardes da Silva. O texto final expressa também alguns resultados do projeto de pesquisa "Produção e circulação de informações e usos do território brasileiro no período atual” (auxílio à pesquisa - Edital Universal-2014-CNPq), coordenado por Adriana Maria Bernardes da Silva.

Recebido para publicação em 9 de janeiro de 2019 Aceito para publicação em 19 de fevereiro de 2019 Publicado em 15 de abril de 2019 